\title{
Manager Attitude Impact on the Performance of Employees "A Case of Jordanian Travel and Tourism Institutions"
}

\author{
Ashraf Mohammad Alfandi ${ }^{1}$ \\ ${ }^{1}$ Department of Tourism Management, Irbid National University, Irbid, Jordan \\ Correspondence: Ashraf Mohammad Alfandi, Department of Tourism Management, Irbid National University, \\ Irbid, Jordan.
}

Received: November 18, 2019

doi:10.5539/ibr.v13n1p136
Accepted: December 6, 2019 Online Published: December 12, 2019

URL: https://doi.org/10.5539/ibr.v13n1p136

\begin{abstract}
The present study aimed to examine the role of manager attitude (MA) on enhancing employee performance (EP) at the tourism and travel institutions (TTI) in Jordan. The study population consists of 3700 employees at the TTI located in the capital of Jordan (Amman) as most of institutions located their (97\%). A randomly sampling technique was employed at the present study. Collected data were analyzed using Statistical Packages for Social Sciences (SPSS) program. The researcher distributed 132 questionnaires, 123 of them were returned, which forms $93 \%$ of the sample. The study found a statistical significant influence of MA on EP in general. More specifically, the results showed that there is a statistically significant impact of MA on the three dimensions of EP (quality of work, quantity of work and speed of work achievement). The researcher accounts these results that the concept of MA helped people at the organization to become more effective in carrying out of their duties to improve organizational performance through the increasing level of individual competences. Finally, further research opportunities could enrich the understanding of MA and EP at the Jordanian TTI has been verified.
\end{abstract}

Keywords: Manager Attitude (MA), Employee Performance (EP), Travel and Tourism Institutions (TTI), Jordan

\section{Introduction}

EP is the key element to achieve organization goals as it increases the effectiveness and efficiency of the organization. It prepares employees to hold future positions in an organization with full capabilities and helps to overcome the deficiencies in any job related area (Elnaga \& Imran, 2013; Khan, Dongping, \& Ghauri, 2014). Henceforth, the failure or success of every business mostly depends on the performance of their employees (McNeese-Smith, 1997). Basically, the employers hire employees based on their communication skills, personality, confidence, and of course their education and experience. Nevertheless, the question remains how we can make an employee work more efficiently and effectively to guaranteeing an EP in order to increase the productivity of any organization?

The literatures show many factors found to have noteworthy influences on the EP such as incentives, the culture of the organization, the working environment as well as MA (Alfandi, 2016; Armstrong, 2000). MA consider as one of the important factors that save time and cost at work (Baum \& Devine, 2007; Kaynak, 2003; Khan et al., 2014; Elnaga \& Imran, 2013). Due to the fact that employees often mimic the dedication that manager's exhibit and pay attention to the way their managers act, employees incorporate their manager's work ethic subconsciously into their own ways. For instance, when a manager of a travel and tourism company ensures that each task is completed to the best of his ability, this attitude will infuse the workplace with the same mindset and positively influence his EP.

\section{Problem of the Study}

MA plays a vital role in improving performance and eventually putting companies in the best position to face competition and stay at the top (Gana \& Bababe, 2011; Jabeen, 2011; Khan et al., 2014). It is proven in the literature that the development of organizations is directly dependent upon the performance of the human element through work quantity, quality, and speed of work achievement, which reflects the overall performance in the organization. Nevertheless, there is an absence of Arabic studies in the tourism industry particularly in Jordan in terms of examining the influences of MA on the EP (Alfandi, 2016). Generally, tourism and hospitality industry facing several difficulties in terms of human resources such as high turnover intention, recruiting, the 
need for training and development, low morale, shrinkage, talent acquisition and the ability to retain good and experienced employees. Some of these problems occur due to the lack strategic interventions of specific MA to any particular situations which impact EP. In this context, positive MA inspire employees to work hard, reduces the costly turnover, and develop a sense of commitment to the company. However, there is nothing more important than measuring the level of EP as a result of their MA with them, not only to see if behavior has changed, but also to find the reasons why change has not happened (Kirkpatrick \& Kirkpatrick, 2005).

While attitudes vary from manager to manager and from industry to another, it is important to find out what influences this attitudes with a view to managing them so that EP can be a force of good. This is particularly significant in the tourism and hospitality industry which is a key service sector where manager's attitude has a drastic impact on EP. With this in mine, the aim of this study is to overcome this issue as well as provides insight for the Jordanian TTI by defining the effect of MA practices on EP at the Jordanian TTI.

\section{Objectives of the Study}

There are three major objectives of the current study. These are;

1) To investigate the meaning and importance of MA to workers at TTI in Jordan.

2) To explore the relationship between MA and EP at TTI in Jordan.

3) To develop guideline for assessing the EP at TTI in Jordan.

The main goal of the current study is to identify the impact of MA on EP at TTI in Jordan. This main objective is divided into the following sub objectives:

1) To identify the influence of MA on quantity of work.

2) To identify the influence of MA on quality of work.

3) To identify the influence of MA on speed of work achievement.

\section{Study Questions}

This study seeks to answer the following main question: Is there an impact of MA on EP?

This main question is divided into the following sub questions:

1) Is there an impact of MA on quantity of work at TTI in Jordan?

2) Is there an impact of MA on quality of work at TTI in Jordan?

3) Is there an impact of MA on speed of work achievement at TTI in Jordan?

\section{Study Hypotheses}

In order to achieve the study objectives, the following main null hypothesis has been developed:

(H0): There is no statistical significant impact of MA on EP.

The main null hypothesis is divided into the following sub hypotheses:

(H01): There is no statistical significant impact of MA given by TTI on their quality of work.

(H02): There is no statistical significant impact of MA given by TTI on their quantity of work.

(H03): There is no statistical significant impact of MA given by TTI on their speed of work achievement

\section{Employee Performance (EP)}

According to Rothwell, Hohne, \& King, (2007), the performance of person, group, or organization deals with the outcomes, results and accomplishments achieved. In case of organization performance, the focus is on the organization ability to meet the customer's needs, compete in the market, and carry out the strategies related to the organization and achievement of the goals (Rothwell et al., 2007). Whereas individual performer related to the people that are performing activities related to work (Heck \& Marcoulides, 1993). It is the goals that organizations seek to complete through their employees. In other words, it is the individuals' responsibilities, activities and duties, that their work consists of, which should be done in the right way with taking into consideration the qualified employees abilities to do them (Al-Rabayah 2003). According to Cooke, (2000) it is the achievement of specified task measured against predetermined or identified standards of accuracy, completeness, cost and speed. Therefore, EP is associated with their feelings, cognition and perceptions about their jobs.

When we talk about the EP we come across the question of why we need to look or evaluate their performance? The answer is that several objectives can be achieved through applying extensive performance evaluation 
systems such as choosing qualified persons whose skills and experiences suite the required work. Hence, assessing performance can offer standard bases used to promote employee by giving incentives in order to increase the production and quality (Al-Rabayah 2003). At the end, evaluation employees increase their morale by appreciating their efforts, which reflects their salaries (Abbas \& Hamadi 2009).

\subsection{How to Measure Performance of the Employees}

EP could be seen and measured in different ways. For instance, EP is the given quality of efforts that could be defined as the error-free performance and matching between the production and the required standards. Others see EP as the amount of the physical or mental energy that the individual spends in a specific period of time in the work. While some focus on the quality and the amount of given efforts, others refers to it as the way in which the work duties are done. For example, performance can be measured through the manner of performance such as measuring problem-solving strategies or in problem detecting. Finally, EP could be measured by looking at the rates of performance, which is the process in which the evaluator increases the employee's productivity in order to determine the efficiency, the quality and the amount of the employee's work in a specific period (Al-Rabayah 2003; Uddin, Luva, \& Hossain, 2013).

In the current study, EP will be measured through the dimensions of: quantity of work, quality of work, speed of work achievement as was suggested by the previous work of Mathis \& Jackson (2009).

\section{MA and EP}

Attitude could be either positive or negative. MA can be seen as a part of managerial series of leadership style. It is the manager ability to impact subordinates to perform at their highest capability. Beside many other variables, the employees' satisfaction about their manager's attitude considers the most important factor that could impact EP (McNeese-Smith, 1997; Mathis \& Jackson, 2009). It is generally agreed that EP could be as low as zero or at peak capacity depending on MA with them. MA plays a critical role in worker performance and job production. If the employees are stratified about their manger attitude with them, job productivity will increase (Alfandi, 2016). In this context, a theory developed that constitutes most about the two-way relationship between the manager and employee. This theory called Leader-Member interaction. This theory assumes that the leader does not treat all subordinates in a similar way and focuses on mutual relations that every leader establishes (Benedicta, 2010; Cole, 2002). If employees are happy with the work they perform, the satisfaction will occur (Horng and Lin 2013). Consequently, the leaders do not have a uniform interaction with the audience since they have limited time and resources (Zhang, Leng, \& Xu, 2019). In the relationship between the leader and the follower, a high level of trust, respect and compliance with obligations are the main determinants of the change relationship (McNeese-Smith, 1997; Seamen \& Eves, 2005).

Manager can exercise their official or unofficial power to given trust and confidence to their employee which will erect high level of EP. This relationship has been confirmed by several previous studies that found manger attitude unbiased behavior toward their employees will lead to high level of EP (Mulder, 2001; Seamen \& Eves, 2005; Khan et al., 2014; Alfandi, 2016).

\section{Methodology}

\subsection{Data Collection}

Books, publications and other several theoretical references relevant to the topic were reviewed in order to cover the theoretical part of the study. Descriptive analytical approach was used through field survey. The study community were employees at TTI in Jordan, and then analyzing the collected data by using statistical analysis program SPSS (Statistical Package for Social Sciences) for testing the hypotheses through regression analysis.

\subsection{Validity Test}

The questionnaire was presented to some experienced instructors at Irbid National University (INU) who are specialized to ensure the superficial validity of the measurement method. Based on their comments, some modifications were made to some paragraphs related to the language structure, clarity and the harmony of the study field. Gronbach Alpha test was used to test the validity of the study's method; the score ranged between $71 \%$ and $82 \%$ for all of the questionnaire's paragraphs, which consider suitable according to the acceptable percentage presented by (Hair, Money, Samouel, \& Page 2007) which is $60 \%$.

\subsection{Measurement Methods}

In order to present the questions of the questionnaire, five points Likert scale was used divided as (1) strongly disagree, (2) disagree, (3) neutral, (4) agree, and (5) strongly agree. Based on these scales, the sum of these scales was 15 , and thus the average is $15 / 5=3$. To measure MA, four items were adopted from Kalkavan \& 
Katrinli, (2014) who previously adopted it from Hackman \& Oldman, (1975).

\section{Results}

\subsection{Study Sample and Their Characteristics}

The study population consists of employees at TTI located in Jordan. According to the Jordanian ministry of tourism and antiques statistics (2019), there are about 4800 employees working in TTI around the kingdom, most of them working in the capital Amman (about 3800). Therefore, the study population was workers at TTI located in the capital of Jordan Amman. A random sampling technique was employed. The study chooses to distribute 132 questionnaires, 123 of them were returned, which forms about $92 \%$ of the sample. The following table extracts the repetitions and percentages of the sample personal information.

Table 1. Study Sample Personal Information

\begin{tabular}{lll}
\hline Gender & Repetition & Percentage \\
\hline Male & 84 & $68 \%$ \\
\hline Female & 39 & $32 \%$ \\
\hline Total & 123 & $100 \%$ \\
\hline Qualification & Repetition & Percentage \\
\hline Diploma or less & 51 & $41 \%$ \\
\hline Bachelor & 66 & $53 \%$ \\
\hline Graduate Studied & 6 & $6 \%$ \\
\hline Total & 123 & $100 \%$ \\
\hline Years of experience & Repetition & Percentage \\
\hline Less than 5 years & 72 & $59 \%$ \\
\hline $5-10$ years & 30 & $24 \%$ \\
\hline $10-15$ years & 12 & $10 \%$ \\
\hline $15-$ more & 9 & $7 \%$ \\
\hline Total & 123 & $100 \%$ \\
\hline Job Description & Repetition & Percentage \\
\hline Manager & 9 & $7 \%$ \\
\hline Chairman & 42 & $34 \%$ \\
\hline Executive & 72 & $59 \%$ \\
\hline Total & 123 & $100 \%$ \\
\hline
\end{tabular}

As we can realize from the table above, the highest percentage was the male sample getting $68 \%$, compare to the females who representing $32 \%$ of the sample. Regarding the study sample qualifications, the higher ratio is for those having BA degree reaching 53\% followed by Diploma and higher educational degrees (41\%) and (6\%) respectively. We can attributes this to the fact that tourism industry in general requires more an experienced more workers rather than those with higher educations. Most of the respondents $(59 \%)$ having less than 5 years of working experience. Those who fall into category of (5 to 10 years of experience) come next reaching $24 \%$ of the respondents, and only $7 \%$ of the respondents having more than 15 years of experience at TTI. Finally, regarding the position title job, 59\% of the respondents were executive's workers followed by Chairman $34 \%$ and finally managers $7 \%$.

\subsection{Descriptive Statistics}

The following section explains the results of the descriptive statistical test of the study variables.

Table 2. Descriptive statistics of quality of work

\begin{tabular}{llll}
\hline Quality of work & Mean & $\begin{array}{l}\text { Standard } \\
\text { Deviation }\end{array}$ \\
\hline 1 & I follow the required quality standards in doing my job & .823 \\
\hline 2 & I am working on improving my work continuously. & 3.4 & .613 \\
\hline 3 & I achieve my work within the required specifications. & 4.2 & 1.030 \\
\hline 4 & I continually try to reduce the errors that occur during my work. & 3.6 & 1.045 \\
\hline 5 & I pay attention to the quality of the services given to the beneficiaries & 3.1 & .894 \\
\hline 6 & I follow the instructions and regulations at work & 3.4 & .992 \\
\hline Grand mean of quality of work & 3.6 & 3.5 \\
\hline
\end{tabular}

The table above shows the attitudes of the study sample towards the quality of work in Jordanian TTI. The arithmetic means ranges between (3.1) in their least range for the part "I continually try to reduce the errors that 
occur during my work." and (4.2) in their highest range for the part "I am working on improving my work continuously". The general arithmetic mean was close to the neutral level with an arithmetic mean reaching (3.5); this shows a good level of the quality of work in Jordanian TTI provided by their employees.

Table 3. Descriptive statistics of quantity of work

\begin{tabular}{llll}
\hline & Quantity of work & Mean & $\begin{array}{l}\text { Standard } \\
\text { Deviation }\end{array}$ \\
\hline 1 & I achieve a larger number of tasks than my work required. & .568 \\
2 & I have the ability to deal with troubles at work & 4.3 & .567 \\
3 & I finish the required work even if it requires extra efforts & 3.1 & .592 \\
4 & I am willing to work harder & 3.1 & .594 \\
Grand Mean of Quantity of work & 3.6 & \\
\hline
\end{tabular}

Table (3) shows the arithmetic means of quantity of work paragraphs that ranged from (3.1) in their least limit to (4.3) in their highest limit. The general arithmetic mean was (3.6) which demonstrate a big percentage of quantity of work for the employees at Jordanian travel and tourism.

Table 4. Descriptive statistics of speed of work achievement

\begin{tabular}{llll}
\hline \multicolumn{5}{c}{ Speed of work achievement } & Mean & \\
\hline 1 & I always try to save time at work. & 3.6 & 1.030 \\
\hline 2 & I provide effort at work. & 3.9 & .956 \\
\hline 3 & I try to achieve greater flexibility in work & 3.6 & .902 \\
\hline 4 & I always find ways to do business tasks easily. & 3.2 & 1.039 \\
\hline Grand mean of Speed of work achievement & 3.6 & \\
\hline
\end{tabular}

The table above (4) explains the attitudes of the sample towards the Speed of work achievement at Jordanian TTI. The arithmetic means ranges from (3.2) in their least limit for the paragraph "I always find ways to do business tasks easily." to (3.9) in their highest limit for the paragraph "I provide effort at work". The general arithmetic mean was close to the neutral level with an arithmetic mean reaching (3.6). The general arithmetic mean reached (3.4) which show a quite good percentage of employees' satisfaction about their speed of achieving work tasks.

Table 5. Descriptive statistics of employee MA

\begin{tabular}{llll}
\hline MA & \multicolumn{1}{c}{ Mean } & $\begin{array}{l}\text { Standard } \\
\text { Deviation }\end{array}$ \\
\hline 1 & $\begin{array}{l}\text { My manager focuses on the company goals and } \\
\text { vision }\end{array}$ & 4.7 & .772 \\
\hline 2 & $\begin{array}{l}\text { My manager believes he can make an impact, even if } \\
\text { it starts out as a small one }\end{array}$ & 3.8 & .884 \\
\hline 3 & $\begin{array}{l}\text { My manager has confidence in others, even if it means helping } \\
\text { others grow and get ready. }\end{array}$ & 2.9 & .771 \\
\hline 4 & $\begin{array}{l}\text { My manager regulates his emotions and tries to minimize } \\
\text { stress and maintain self-control. }\end{array}$ & 3.2 & .977 \\
\hline 5 & $\begin{array}{l}\text { My manager identifies opportunities, workarounds, and } \\
\text { contingency plans to keep going. }\end{array}$ & 3.7 & .674 \\
\hline 6 & $\begin{array}{l}\text { My manager genuinely wants to succeed and to see others } \\
\text { succeed, too. }\end{array}$ & 3.1 & .585 \\
\hline 7 & $\begin{array}{l}\text { My manager looks for the good in others and assumes good } \\
\text { intent vs. being suspicious or jaded. }\end{array}$ & 2.8 \\
\hline
\end{tabular}

The table above (5) explains how the employees perceived their MAs of the sample at Jordanian TTI. The arithmetic means ranges from (2.8) in their least limit for the paragraph "My manager looks for the good in others and assumes good intent vs. being suspicious or jaded" to (4.7) in their highest limit for the paragraph "My manager focuses on the company goals and vision ". The general arithmetic mean was close to the neutral level with an arithmetic mean reaching (3.5) which shows a quite good percentage of employees' satisfaction about their manager's attitude. 


\subsection{Correlation Analysis}

In order to obtain understanding of the relationship between variable used in this study, the computation of the Pearson correlation coefficients was performed. Correlation analysis was conducted on the data of the survey based on the independent variable of MA against the dependent variables of quality of work, quantity of work and speed of work achievement. A majority of correlation values of the variables showed correlations coefficients with values below .54. These generally indicate weak and medium associations between variables. The correlations within the three EP dimensions are examined and show that are significantly correlated. In terms of MA and EP dimensions, the correlations are generally positive. A weak correlation has been found between MA and the speed of achievement $(\mathrm{r}=.14)$ and medium correlations between the quality and quantity of work with MA $(\mathrm{r}=.34 ; .37)$ respectively. These findings give indication that MA is not the major (or only) variable influencing the EP.

To examine the multicollianearity among the variables in this study, variance inflated factor (VIF) and tolerance tests were adopted. Tolerance is the amount of variability of the selected independent variable not explained by the other independent variables (Hair et al., 2007), whereas VIF is the opposite of tolerance value. For the purpose of this study the two tests were conducted to determine the multicollianearity assumption. The results exposed that the values of VIF and tolerance used showed no multicollianearity between the study variables as their values less than 10 for the VIF and more than 0.10 for tolerance as suggested by Field, (2005).

\subsection{Hypotheses Testing}

To test the hypothesis of the study, multiple liner regressions were used. The interruption of the regression analysis is based on the standardized coefficient beta, $\mathrm{R}$ square and if its calculated value was higher than its tabulated value which provides evident whether to support the hypotheses stated earlier with taking into consideration the sensitivity of regression analysis to outliers.

For the main hypothesis, the table (6) below shows that the R square obtained indicates that MA account of $18.9 \%$ of the variation in the EP. The value of Beta is (0.434), and the value of calculated F (13.544) which is higher than tabulated F value (1.97) at the confidence level $(\alpha \leq 0.05)$, and the value of statistical significance level is (0.000) which is less than the value of the confidence level $(\alpha \leq 0.05)$. Based on the result, the null hypothesis was rejected and thus the alternative hypothesis is accepted, in an indication that there is a statistical significant impact of MA on EP.

Table 6. Results of the regression analysis for testing study hypotheses

\begin{tabular}{|c|c|c|c|c|c|c|}
\hline & Variables Dependent & $\begin{array}{c}\mathrm{F} \\
\text { Calculated } \\
\end{array}$ & $\begin{array}{c}\mathrm{F} \\
\text { Tabulated }\end{array}$ & $\mathrm{R}^{2}$ & Beta & $\begin{array}{l}\text { Sig. F; } \\
\text { p }<0.01\end{array}$ \\
\hline Main hypothesis 1 & EP & 13.544 & 1.97 & 0.189 & 0.434 & $0.00 * *$ \\
\hline Sub hypothesis 1-1 & Quantity of work & 08.564 & 1.32 & 0.054 & 0.201 & $0.00 * *$ \\
\hline Sub hypothesis $1-2$ & Quality of work & 07.788 & 1.55 & 0.069 & 0.132 & $0.00 * *$ \\
\hline Sub hypothesis $1-3$ & Speed of work achievement & 12.545 & 1.84 & 0.112 & 0.211 & $0.00 * *$ \\
\hline
\end{tabular}

As shown in the table above (6), in terms of the influence of MA on quantity of work, the result of simple regression shows that MA account for 5.4\% of the variance. The value of Beta is $(0.201)$, and the value of calculated F (8.564) which is higher than tabulated F value (.132) at the confidence level $(\alpha \leq 0.05)$, and the value of statistical significance level is $(0.000)$ which is less than the value of the confidence level $(\alpha \leq 0.05)$. Based on the result, the null hypothesis was rejected and thus the alternative hypothesis is accepted, in an indication that there is a statistical significant impact of MA on the quantity of work.

In terms of the influence of MA on the quality of work, the result of simple regression shows that MA accounts for $6.9 \%$ of the variance. The value of Beta is (0.132), and the value of calculated F (7.788) which is higher than tabulated $F$ value (1.55) at the confidence level $(\alpha \leq 0.05)$, and the value of statistical significance level is $(0.000)$ which is less than the value of the confidence level $(\alpha \leq 0.05)$. Based on the result, the null hypothesis was rejected and thus the alternative hypothesis is accepted, in an indication that there is a statistical significant impact of MA on the quality of work.

In terms of the influence of MA on the speed of work achievement, the result of simple regression shows that MA accounts for $11 \%$ of the variance. The value of Beta is $(0.211)$, and the value of calculated $F(12.545)$ which is higher than tabulated $\mathrm{F}$ value (1.84) at the confidence level $(\alpha \leq 0.05)$, and the value of statistical significance level is $(0.000)$ which is less than the value of the confidence level $(\alpha \leq 0.05)$. Based on that, the null hypothesis 
was rejected and thus the alternative hypothesis is accepted, in an indication that there is a statistical significant impact of MA on the speed of work achievement.

In the present study the beta values were used in order to examine which factor has the most effect by MA. The findings show that the beta for quality of work is $(0.13)$ and the beta for quantity o work is $(0.20)$, while the beta for speed of work achievement is (0.21). The result indicates that MA has the most influence on the speed of work achievement flowed by quantity of work and finally the quality of work.

\section{Conclusion and Recommendation}

The result showed that the perception of the employees at the Jordanian TTI regarding the MA in their institutions was quite high. In particular, they believe that their MA influence and develop their skills and performance. They believed that their MA helped them to achieve a larger number of tasks and give them the ability to deal with troubles at work in addition to improve their work continuously. Weak and medium associations between study variables are found. In terms of MA and EP dimensions, the correlations are generally positive. A weak correlation has been found between MA and the speed of achievement $(r=.14)$ and medium correlations between the quality and quantity of work with MA $(\mathrm{r}=.34 ; .37)$ respectively.

The study found a statistical significant impact of MA on EP in general. More specifically, the results showed that there is a statistically significant impact of MA on the three dimensions of EP (quality of work, quantity of work and speed of work achievement). The researcher reply these results that the concept of MA can help employees to become more effective in carrying out of their duties to improve organizational performance through the increasing level of individual competences. Based on the study results, we exhibit here the most important recommendations for Jordanian TTI that are still under study as follows; 1) more attention should be paid to the MA as it found to have several advantages. 2) The success of TTI relies, in the first place, upon EP, as such; they should take care of workers as they do of beneficiaries. 3) Managers should take credits for others' work and appreciation or give recognition to employees. 4) The results showed that employees think that their manager has not enough confidence in others, even if it means helping others grow and get ready. If managers refuse to let anything to go without approval, it results in bottlenecks. Therefor it is recommended that managers should focus more on appreciating instances where their team exceeds their expectations which will be a source of demotivation.

The present study is limited to examining how MA at the TTI in Jordan influencing EP from the point of view of the chairmen of these institutions in addition to the employees. Moreover, this study dealt with TTI located in the capital city of Jordan, Amman, as most of the tourism institutions (about 97\%) are found there. As for the period of the study, it is noteworthy that the study was conducted in 2019. MA alone is not the only answer to improve EP, however, the responsibility of managers to provide a positive attitude has become greater than before. Therefore, future research avenues could be conducted in tourism industry but in different sectors such as in five-star or four-start hotels, or incorporating different variables that have explanations regarding EP such as incentives, communication, and turnover intention and working environment. The field does not yet have definitive knowledge about the role of MA in influencing their EP, especially in the field of TTI. Much remains to be explored on how, when, where and why managers influence firms. We hope that the current study adds another small piece to this large puzzle.

\section{References}

Abbas, A., \& Hammadi, S. (2009). Incentives and their Effects on Performance. Tanmiat Alrafidain, 31(93), 105-123. https://doi.org/10.33899/tanra.2009.161831

Alfandi, A. (2016). Selected Antecedents Impacts on Employees performance. Paper presented at the 2016 Prague International Academic Conference. September 4-7, 2016. Prague, Czech Republic. Retrieved from https://www.globalacademicinstitute.com/wp-content/uploads/2016-prague-conference-proceedings.pdf

Al-Rabayah, A. (2003). Human Resource Management. Amman, Dar Al-Safaa.

Armstrong, M. (2000). Understanding MA. Human Resource Management Practice. Kogan page limited, London. pp.543.

Baum, T., \& Devine, F. (2007). Skills and training in the hotel sector: The Case of front office employment in Northern Ireland. Tourism and Hospitality Research, 7(3), 269-280. https://doi.org/10.1057/palgrave.thr.6050046

Benedicta, A. (2010). The Impact of Training on Employee Performance: A Case Study of HFC Bank in Ghana. International Journal of Science and Research (IJSR), India, Online ISSN: 2319-7064. 
Cole, G. A. (2002). Personnel and Human Resource Management (5th ed.). York Publishers, Continuum London, UK.

Cooke, F. L. (2000). Human Resource Strategy to improve Organizational Performance: a route for British firms. Manchester School of Management. ESRC Future of work programe. EWERC, UMIST. Retrieved from https://pdfs.semanticscholar.org/6182/c3862dfa21ddffe49e185627f30c78940041.pdf

Elnaga, A., \& Imran, A. (2013). The Effect of Training on Employee Performance. European Journal of Business and Management, 5(4).

Field, A. (2005). Discovering statistics using SPSS. London: Sage.

Galanou, E., \& Priporas, C. (2009). A model for evaluating the effectiveness of middle managers MA courses: evidence from a major banking organization in Greece. International Journal of MA and Development, 221-245. https://doi.org/10.1111/j.1468-2419.2009.00329.x

Gana, A. B., \& Bababe, F. B. (2011). The Effects of Motivation on Workers Performance (a case study of Maiduguri Flour Mill Ltd. Borno State, Nigeria). Continental J. Social Sciences, 4(2), 8-11. Retrieved from https://www.academia.edu/769482

Hackman, R. J., \& Oldham, G. R. (1975). Development of the Job Diagnostic Survey. Journal of Applied Psychology, 60(2), 159- 170. https://doi.org/10.1037/h0076546

Hair, J. F., Money, A. H., Samouel, P., \& Page, M. (2007). Research Methods for Business. John Wiley \& SoNn.

Heck, R. H., \& Marcoulides, G. A. (1993). Organizational Culture and Performance: Proposing and Testing a Model. Organization Science, 4(2), 209-225. https://doi.org/10.1287/orsc.4.2.209

Horng, J. S., \& Lin, L. (2013). Training needs assessment in a hotel using 360 degree feedback to develop competency-based MA. Journal of Hospitality and Tourism Management, 20, 61-67. https://doi.org/10.1016/j.jhtm.2013.06.003

Jabeen, M. (2011). Impact of Performance Appraisal on Employees Motivation. European Journal of Business and Management, 3(4). Retrieved from https://www.academia.edu/4631737

Jordanian Ministry of Tourism and Antiques. (2019). 2019 statistics. Retrieved from https://www.mota.gov.jo/Contents/stat2019_2ndAr.aspx

Kalkavan, S., \& Katrinli, A. (2014). The Effects of Managerial Coaching Behaviors on the Employees' Perception of Job Satisfaction, Organizational Commitment, and Job Performance: Case Study on Insurance Industry in Turkey. Procedia - Social and Behavioral Sciences, 150, 1137-1147. https://doi.org/10.1016/j.sbspro.2014.09.129

Kaynak, H. (2003). The relationship between total quality management practices and their effects on firm performance. Journal of Operations Management, 21(4), 405-435. https://doi.org/10.1016/S0272-6963(03)00004-4

Khan, I., Dongping, H., \& Ghauri, T. A. (2014). Impact of Attitude on Employees Performance: A Study of Textile Industry in Punjab, Pakistan. World Applied Sciences Journal, 30, 191-197. Retrieved from https://www.idosi.org/wasj/wasj30(icmrp)14/25.pdf

Mathis, R. L., \& Jackson, J. H. (2009). Human Resource Management. Mason, OH, USA: South-Western Cengage Learning. pp. 324.

McNeese-Smith, D. K. (1997). The Influence of Manager Behavior on Nurses' Job Satisfaction, Productivity, and Commitment. JONA The Journal of Nursing Administration, 27, 9. Retrieved from https://www.researchgate.net/publication/13921449

Mulder, M. (2001). Customers Satisfaction with Training Program. Journal of European Industrial MA, 25(6), 321-331. https://doi.org/10.1108/03090590110401791

Rothwell, W. J. C. K., Hohne, C. K., \& King, S. B. (2007). Human Performance Improvement. Building Practitioner Competence. Gulf Publishing Company.

Salas, E., \& Cannon-Bowers, J. A. (2001). The science of Training: A decade of progress. Annual Review of Psychology, 52, 471-499. https://doi.org/10.1146/annurev.psych.52.1.471

Seamen, P., \& Eves, A. (2005). The management of food safety-the role of food hygiene training in the UK service sector. International Journal of Hospitality Management, 25(2), 278-296.

https://doi.org/10.1016/j.ijhm.2005.04.004 
Uddin, M. J., Luva, R., \& Hossain, S. (2013). Impact of Organizational Culture on Employee Performance and Productivity: A Case Study of Telecommunication Sector in Bangladesh. International Journal of Business and Management, 8(2). https://doi.org/10.5539/ijbm.v8n2p63

Zhang, C., Meiqing, L. M., \& Xu, S. (2019). Can a Leader's Positive Evaluation Improve Occupational Satisfaction of Employees? Based on the Empirical Investigation of a Real Estate Enterprise G Province Branch. International Business Research, 12(11). https://doi.org/10.5539/ibr.v12n11p57

\section{Copyrights}

Copyright for this article is retained by the author(s), with first publication rights granted to the journal.

This is an open-access article distributed under the terms and conditions of the Creative Commons Attribution license (http://creativecommons.org/licenses/by/4.0/). 